\title{
Fundamental Investigation of LCA of Cross Tie
}

\author{
Hiroshi UEDA \\ Engineer, Inorganic Material G., \\ Material Technology Development Div., \\ Technological Development Dept. \\ (Currently : East Japan Railway Company)
}

\section{Hideyuki TAKAI}

Chief Engineer, Track Geometry \& Maintenance G., Track Technology Development Div., Technological Development Dept.

\section{Taro TSUJIMURA}

Chief Engineer, Metallic Material G., Material Technology Development Div., Technological Development Dept.

\section{Manabu EMOTO}

Engineer, Track Structure \& Component G., Track Technology Development Div., Technological Development Dept. (Currently : East Japan Railway Company)

As environmental preservation becomes an increasingly important issue on a global scale, railway enterprises are also required to assess and reduce environmental loads of materials used in railway systems. Such loads are mainly related to vehicles and facilities. In this study, we estimated the environmental load of railway facilities, and conducted a case study on four types of cross tie (wood, concrete, synthetic and steel) by applying the LCA method at the production stage. As a result, we found that $\mathrm{CO}_{2}$ emission from total ties in Japan was about 55,000 tons per year.

Keywords : environment, environmental impact, cross tie, LCA

\section{Introduction}

As environmental preservation becomes an increasingly important issue on a global scale, railway enterprises are also required to assess and reduce environmental loads of materials used in railway systems. Such loads mainly consist of vehicle-associated factors (e.g. energy for operating) and railway facilities (structures, tracks, stations, etc). However, it is difficult to assess the whole load of railway facilities because they are enormous in kind, number and length. There are very few studies which estimate the environmental loads of railway facilities. This report adopts cross ties for a case study to estimate the loads of railway facilities, and estimates the loads of different materials.

\section{Number of ties in Japan}

We first investigated "Annual Report on Japanese Railways ${ }^{1) " ~ t o ~ c h e c k ~ t h e ~ n u m b e r ~ o f ~ t i e s ~ u s e d ~ i n ~ J a p a n . ~}$ Since the data were shown in length of track, we calculated the number of ties at the rate of 39 ties $/ 25 \mathrm{~m}$ that is a popular tie spacing in Japan. Table 1 shows the number of ties calculated. The number of total ties used in Japan is about 65 millions. When broken down by material kind, there are about 36 million concrete ties (55\%), which are the most popular, 27 million wood ties (42\%), and 2 million of other kinds of ties (4\%). Examples of other kinds of ties are organic resin (called synthetic ties) and steel ties.
Table 1 Number of ties used in Japan

\begin{tabular}{|l|r|r|r|r|}
\hline \multirow{2}{*}{ Organization } & \multicolumn{3}{|c|}{ Kind } & \multirow{2}{*}{ Total } \\
\cline { 2 - 4 } & Concrete & Wood & Other & \\
\hline JR Hokkaido & 1,811 & 2,657 & 361 & 4,829 \\
JR East & 12,775 & 6,922 & 107 & 19,805 \\
JR Central & 3,432 & 1,726 & 32 & 5,190 \\
JR West & 5,719 & 5,675 & 1,344 & 12,738 \\
JR Shikoku & 356 & 938 & 107 & 1,402 \\
JR Kyusyu & 1,838 & 2,194 & 44 & 4,076 \\
JR Freight & 120 & 550 & 26 & 697 \\
\hline JR Total & 26,053 & 20,662 & 2,022 & 48,737 \\
\hline Major Private & 5,945 & 2,046 & 90 & 8,082 \\
Railways & & & & \\
Small Scale & 2,171 & 4,323 & 193 & 6,687 \\
Private Railways & & & & \\
Teito Rapid & 613 & 136 & 1 & 751 \\
Transit Authority & 998 & 180 & 8 & 1,186 \\
Public Railways & 9,728 & 6,686 & 292 & 16,705 \\
\hline non-JR Total & 35,781 & 27,347 & 2,314 & \multirow{2}{*}{$(\times 1,000)$} \\
\hline Total & \multicolumn{3}{|c|}{65,442} & \\
\cline { 2 - 3 } & & & & \\
\hline
\end{tabular}

\section{LCA of ties}

To estimate the environmental loads, we used the Life Cycle Assessment (LCA) method. Manufactured products undergo several stages during their lifetime (See Fig. 1), that is producing stage, service stage and the waste treatment stage in this order. If the manufactured products are reused or recycled, the waste treatment stage continues to the production stage. Therefore, the material itself forms several life cycles. LCA is the method to estimate the environmental loads at every stage. This method provides data for comparison of environmental loads between manufactured products. It enables therefore to select products of relatively small loads. But, LCA is a 


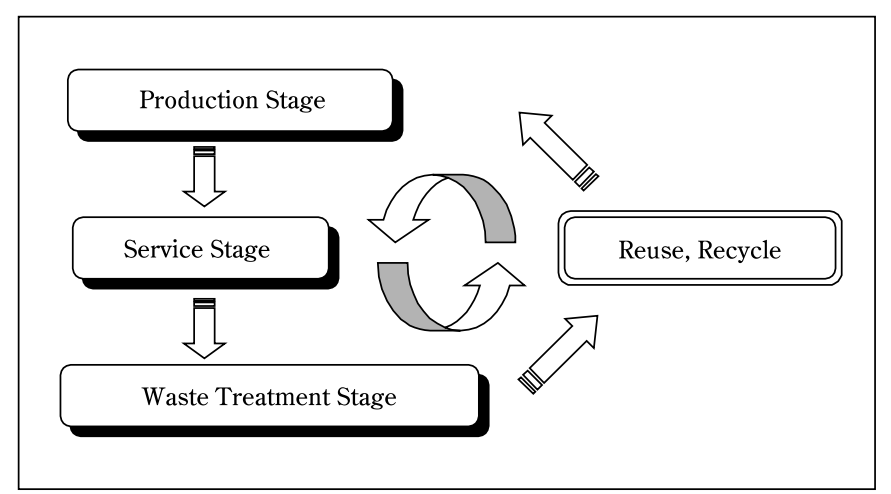

Fig. 1 Life Cycle Assessment

method under development so the output data is sometimes different even for the same manufactured products because of difference in data source of raw materials or other reasons. Consequently, we need to clarify the data used and calculation conditions. If we use the LCA method, we need to arrange the following steps;

(1) Decide the purpose and scope

(2) Collect the inventory analysis data

(3) Estimate the environmental loads

The relationships of environmental loads between materials are boundless. First we must decide the purpose and scope of estimation. Secondly, we investigate the mass of each raw material making up the manufactured products and energy used because the output data is influenced by these factors. After having obtained these data, we can estimate the environmental loads.
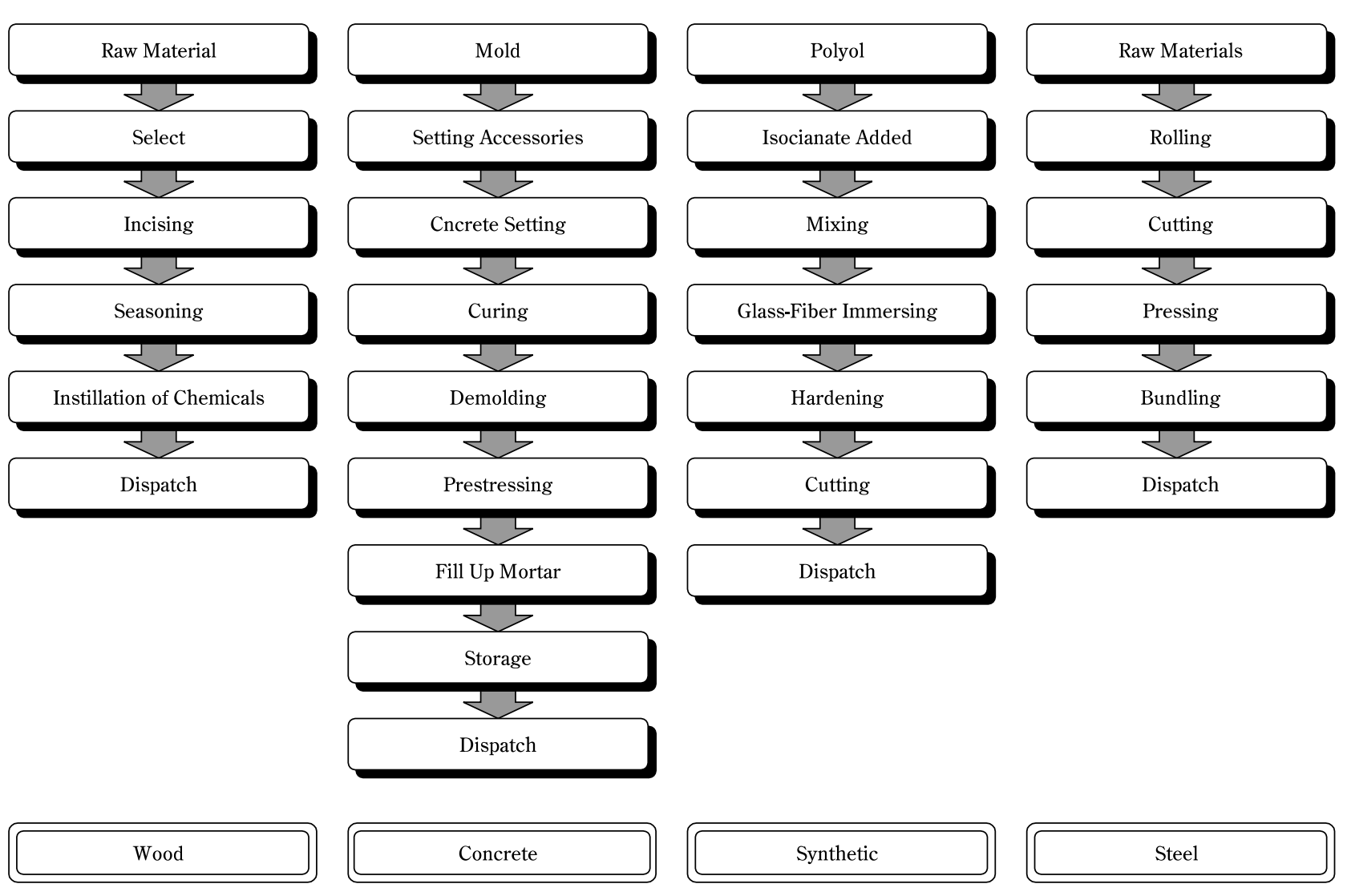
was discussed because no data was available on the service stage and waste treatment stage. So, this does not make a completely constructed LCA.

\section{2 Inventory analysis}

Table 2 shows the materials used and mass of each tie. For wood ties, several kinds of woods are used, which are different in production age or area. At present time, Kempas from Malaysia is the most popular. Creosote is used as antiseptic. This is the important material for elongating the lifetime of wood. Concrete tie is made of concrete, prestressed concrete bar, nut, bearing plate and mortar. The bar, nut and plate are made of steel. The mortar is used for filling up of the hole that is formed in prestressing. Synthetic tie is made of urethane resin, so the raw materials of synthetic tie are polyether polyol, 4,4'-diphenylmethane-diisocyanate (MDI) and glass-fiber. Steel tie is made of steel only.

Figure 2 shows the manufacturing method of each kind of cross tie, and Table 3 shows the energy consumed in production. The data were calculated from the energy

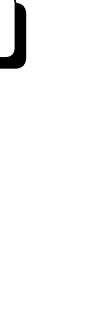
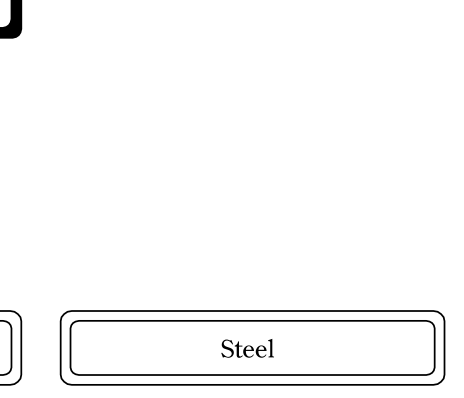

Fig. 2 Manufacturing method of each kind of cross tie 
Table 2 Material and mass of tie

\begin{tabular}{l|l|c}
\hline Kind & Material & Mass [kg] \\
\hline Wood & Wood (Kempas) & $56 \sim 58$ \\
& Creosote & 14 \\
Concrete & Concrete & 155 \\
& Prestressed Concrete Bar & 4.8 \\
& Nut & 0.15 \\
& Bearing Plate & 1.87 \\
& Mortor & 0.9 \\
Synthetic & Polyether Polyol & 8.96 \\
& $*$ MDI & 12.72 \\
Steel & Glass-Fiber & 21.76 \\
\hline
\end{tabular}

*MDI : 4,4'-Diphenylmethane-diisocyanate

Table 3 Energy consumed in production

\begin{tabular}{c|c|c|c}
\hline Kind & Electric power $[\mathrm{kWh}]$ & Light oil $\left[\mathrm{dm}^{3}\right]$ & Heavy oil $\left[\mathrm{dm}^{3}\right]$ \\
\hline Wood & 0.52 & 0.057 & 0.817 \\
Concrete & 1.945 & 0.032 & 0.702 \\
Synthetic & 17.64 & - & 0.77 \\
Steel & 5 & - & 0 \\
\hline
\end{tabular}

used per month divided by the number of ties produced.

\section{3 Estimation of $\mathrm{CO}_{2}$ emission}

\section{3. 1 Conditions}

Based on this inventory data, we calculated the $\mathrm{CO}_{2}$ emission by using "Sima Pro 3" software. As we couldn't obtain the data of creosote, it was excluded from the estimation.

\section{3. $2 \mathrm{CO}_{2}$ emission from ties}

Table 4 shows the $\mathrm{CO}_{2}$ emission from one tie. Wood ties emit the least amount of $\mathrm{CO}_{2}$, and synthetic ties the most. These data involve the $\mathrm{CO}_{2}$ emission at the collection and the transportation of the raw materials.

Table $4 \mathrm{CO}_{2}$ emission from one tie

\begin{tabular}{l|c}
\hline Kind & $\mathrm{CO}_{2}$ emission $[\mathrm{kg}]$ \\
\hline Wood & 11.3 \\
Concrete & 44.1 \\
Synthetic & 99.3 \\
Steel & 48.0 \\
\hline
\end{tabular}

\section{Table 5 Lifetime of ties}

\begin{tabular}{l|c}
\hline Kind & Lifetime [year] \\
\hline Wood & 15 \\
Concrete & 50 \\
Synthetic & 50 \\
Steel & 50 \\
\hline
\end{tabular}

\section{3. 3 Effect of lifetime}

The lifetime is different from one kind of tie. Furthermore it is difficult to decide the precise lifetime because various factors (laying condition, quality of tie, etc) are involved. Therefore, we assumed the average lifetime shown in Table 5.

Figure 3 shows the data of $\mathrm{CO}_{2}$ emission divided by the lifetime. This gives the $\mathrm{CO}_{2}$ emission per year. Wood ties are by no means insignificant in terms of environmental load. Synthetic ties emit more $\mathrm{CO}_{2}$ than other kinds of ties. The emission from synthetic ties is mainly due to MDI, so it is effective to reduce the $\mathrm{CO}_{2}$ emission from MDI.

\section{Total $\mathrm{CO}_{2}$ emission from ties}

Total $\mathrm{CO}_{2}$ emission from type-k ties can be calculated by this equation.

$$
a_{t o t a l, k}=\left(a_{k} / t_{k}\right) \times n_{k}
$$

where $a_{\text {total, } k}, a_{k}, t_{k}, n_{k}$ mean total $\mathrm{CO}_{2}$ emission from type-k ties, $\mathrm{CO}_{2}$ emission from one tie, lifetime of tie and number of ties in Japan, respectively. By this equation, we calculated the total $\mathrm{CO}_{2}$ emission as follows.

(1) Wood tie : $\{11.3(\mathrm{~kg} /$ piece) $/ 15$ (years) $\} \times 27,347,000$ (pieces) $\fallingdotseq 20,000$ (tons/year)

(2) Concrete tie : $\{44.1(\mathrm{~kg} /$ piece $) / 50($ years $)\} \times 35,781,000$ (pieces) $\fallingdotseq 32,000$ (tons/year)

Since we could obtain no data on the number of synthetic ties and steel ties, we divided the number of other ties $(2,314,000$ pieces $)$ into two equal parts, and assumed one part $(1,157,000$ pieces $)$ as synthetic ties and the other as steel ties.

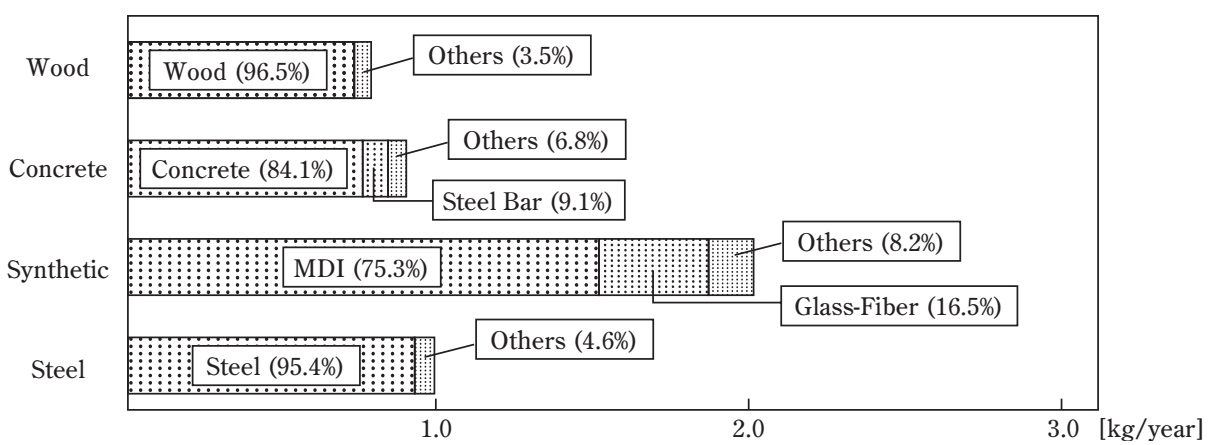

Fig. $3 \mathrm{CO}_{2}$ emission from each tie per year 
(3) Synthetic tie : $\{99.3(\mathrm{~kg} /$ piece $) / 50$ (years) $\} \times 1,157,000$ (pieces) $\fallingdotseq 2,000$ (tons/year)

(4) Steel tie : $\{48.0(\mathrm{~kg} /$ piece) $/ 50$ (years) $\} \times 1,157,000$ (pieces) $\fallingdotseq 1,000$ (tons/year)

Total $\mathrm{CO}_{2}$ emission from all kinds of ties can be calculated by summing up each $a_{\text {total, } k}$ as shown by this equation.

$$
\mathrm{A}=\Sigma a_{t o t a l, k}
$$

Where $\mathrm{A}$ is total $\mathrm{CO}_{2}$ emission from all kinds of ties. Total $\mathrm{CO}_{2}$ emission from all kinds of ties is 55,000 (tons/ year) as shown in Table 6.

Table 6 Total $\mathrm{CO}_{2}$ emission from all kinds of cross tie

\begin{tabular}{l|c}
\hline Kind & $\mathrm{CO}_{2}$ Emission (ton/year) \\
\hline Wood & 20,000 \\
Concrete & 32,000 \\
Synthetic & 2,000 \\
Steel & 1,000 \\
\hline Total & 55,000 \\
\hline
\end{tabular}

\section{Summary}

We estimated the environmental loads of railway facilities by performing a case study on ties. Ties made of four kinds of materials (wood, concrete, synthetic and steel) were selected for estimating the $\mathrm{CO}_{2}$ emission by the LCA method at the production stage. This study proved that $\mathrm{CO}_{2}$ emissions from concrete and steel ties were relatively low. Synthetic ties emit more $\mathrm{CO}_{2}$ than other kinds of ties. The emissions from synthetic ties are mainly due to MDI. It is effective, therefore, to reduce the $\mathrm{CO}_{2}$ emission from MDI. In Japan, total $\mathrm{CO}_{2}$ emission from all ties at the production stage is about 55,000 tons in weight per year.

\section{Reference}

1) "Annual Report on Japanese Railways" (in Japanese), Supervised by Railway Department, Ministry of Transport, 1997 